\title{
El régimen de los moderados
}

\author{
William Richard Rector
}

$\mathrm{L}$ a segunda década del siglo $\mathrm{xx}$ trajo la revolución, tanto a México como a Rusia. En los dos casos, al inicio de cada revolución hubo un breve periodo que se ha denominado el régimen de los moderados, en particular en la obra de Crane Brinton. ${ }^{1}$ Esta fase se percibía como una victoria sobre el antiguo régimen y parecía simbolizar una nueva cooperación y conciliación entre los revolucionarios vencedores y los reaccionarios derrotados. A primera vista, este periodo parecía representar el restablecimiento de la ley y el orden. En realidad las aguas se hallaban revueltas bajo la superficie: agitación por intrigas políticas, rivalidad entre facciones y conflictos de clase desencadenados por el derrumbe del antiguo gobierno.

En ambos países esta agitación finalmente habría de anular el régimen de 147.

1 Vease Brinton, Anatomy, 1965, pp. 121. los moderados y en el proceso derrocaría a los dos líderes que habían llegado a simbolizar los objetivos de estos regímenes, en México: Francisco I. Madero y en Rusia: Alexander Fyodorovich Kerensky.

El propósito de este artículo es examinar el desempeño de estos dos hombres como líderes; determinar hasta qué grado sus propios fracasos como dirigentes contribuyeron a la decadencia y caída de los moderados. Al mismo tiempo, este trabajo también busca un equilibrio entre los extremos teóricos del determinismo estructural y la libertad de la acción individual.

iFueron las condiciones estructurales de la revolución las responsables de la caída de los moderados?, o por el contrario, ifallaron los moderados porque no eran aptos para gobernar? La verdad, como siempre, radica en algún punto intermedio.

La primera parte del artículo se ocupa de estas preguntas. La segunda 
presenta una breve exposición sobre los antecedentes políticos e ideológicos de los dos líderes, seguida de una evaluación crítica de algunas de las decisiones que tomaron mientras estaban en el poder.

\section{UN MARCO TEÓRICO}

Para encontrar un equilibrio entre los factores estructurales y la función del liderazgo, se debe empezar por plantear dos preguntas. En primer lugar, icuáles son las condiciones estructurales que originan una revolución triunfante? y, en segundo, ¿cuáles son los factores psicológicos que producen un líder revolucionario de éxito?

En la obra de Theda Skocpol puede encontrarse una respuesta a la primera pregunta. En su libro States and social revolutions, la autora se concentra en el papel del Estado y de su burocracia durante una crisis revolu. cionaria. Skocpol define los Estados como organizaciones preparadas para mantener el control de los territorios y poblaciones nacionales y para entrar en rivalidad militar potencial o efectiva con otros estados del sistema internacional. ${ }^{2}$

En el antiguo régimen, el Estado se desintegra porque ya no puede seguir cumpliendo con los requerimientos de estas dos prioridades: la conservación del orden interno y la rivalidad externa con otros estados. El viejo Estado, atrapado entre la presión interna y la exterior, no puede continuar exis-

2 Véase Skocpol, States, 1979, p. 22. tiendo; prácticamente deja de existir durante la crisis revolucionaria.

Así, de acuerdo con Skocpol, el éxito de una revolución depende de la creación y consolidación de un nuevo Estado, del que puede decirse que surge como un fénix de las cenizas del viejo. ${ }^{3}$

Parecería entonces que la consolidación del poder y la construcción de un nuevo aparato estatal tendrían que ser el objetivo de toda revolución triunfante y de todo líder revolucionario de éxito. Esto nos lleva a nuestra segunda pregunta. Desafortunadamente, la obra de Skocpol no analiza a fondo esta cuestión; los dirigentes revolucionarios son para la autora poco más que "actores que luchan por sostener y hacer valer sus derechos a la soberanía del Estado". "Esta observación tiene un viso de verdad, pero no basta para explicar por qué algunos líderes pudieron conservar el poder y otros no.

$\mathrm{Si}$, como Skocpol sostiene, las condiciones estructurales de la propia revolución definen lo que es posible e imposible dentro de tal revolución, 5 entonces un dirigente revolucionario debería ser capaz de percibir las "concatenaciones de posibilidades e imposibilidades", creadas por dichas condiciones, para poder desempeñar un papel significativo como líder. La ideología de un líder revolucionario específico es lo que determina la forma en que éste percibe tales condiciones y cómo actuará sobre ellas. Éste es un as-

\footnotetext{
3 Ibid., pp. 161-163

4 Ibid., p. 164.

slbid., p. 171.
} 
pecto del enfoque situacionista planteado por Mostafá Rejai y Kay Phillips.

Rejai y Phillips examinan los factores que influyen en la personalidad e ideología de los líderes revolucionarios a lo largo de sus vidas e intentan relacionar estos factores con los papeles que desempeñarán en el contexto de la revolución:

Nuestro postulado inicial es más bien de sentido común: los dirigentes revolucionarios provienen de un contexto sociohistórico particular. Sus antecedentes sociales y sus experiencias de socialización les imbuyen un conjunto de normas y valores y los preparan para los papeles políticos que les corresponderá desempeñar en el futuro. Por el mismo motivo, están en posición de captar, interiorizar y articular de una manera convincente los miedos, frustraciones, esperanzas y deseos de sus pueblos. $^{6}$

El liderazgo revolucionario sigue siendo sólo potencial hasta que la "situación" -la crisis revolucionariallega a impulsar al líder potencial hacia su papel de liderazgo real. Como se indica arriba, la forma como reaccionan a esta situación depende de los factores personales psicológicos e ideológicos que los motivan y que los hacen únicos como individuos. ${ }^{7}$

Si se parte de estas premisas, el papel del liderazgo revolucionario, como se define en este artículo, está determinado por dos factores. Por una parte, están las oportunidades -las "posibili-

6 Véase Rejai y Phillips, Leaders, 1979, p. 55.

7 Ibid., p. 57. dades e imposibilidades"-creadas por la propia revolución. Por la otra, están las influencias ideológicas y psicológicas que guían y limitan el comportamiento del dirigente revolucionario. Para que la revolución tenga éxito, la construcción del Estado y la consolidación del poder deben forzosamente surgir de los dos factores mencionados. Con esta base se estudiarán los fracasos de Madero y Kerensky.

\section{ANTECEDENTES POLÍTICOS E IDEOLOGíA}

¿Quiénes eran Madero y Kerensky? ¿En qué creian y por qué luchaban?

Analizar todos los factores que influyeron en las vidas de estos dos hombres se alejaría bastante del alcance de este artículo. Sin embargo, hay varios temas comunes en sus historias personales que merecen comentarse en el breve esbozo biográfico que se presenta a continuación.

Tanto Madero como Kerensky crecieron en un ambiente predominantemente rural y es significativo el hecho de que ninguno de los dos provenía de las clases populares. Kerensky era hijo de un prominente maestro de escuela, una profesión de la clase media alta, que merecía cierto respeto (por lo menos en la Rusia zarista). Nació en la ciudad de Simbirsk a orillas del río Volga, una ciudad que él describe como "la más atrasada de las capitales provinciales rusas". ${ }^{8}$ Por obra del destino, esa ciudad ahora se llama Ulyanovsk, en honor de otro de sus hijos famosos: un tal Vladimir Ilich Ulianov,

\footnotetext{
${ }^{8}$ Kerensky, Russia, 1965, p. 3.
} 


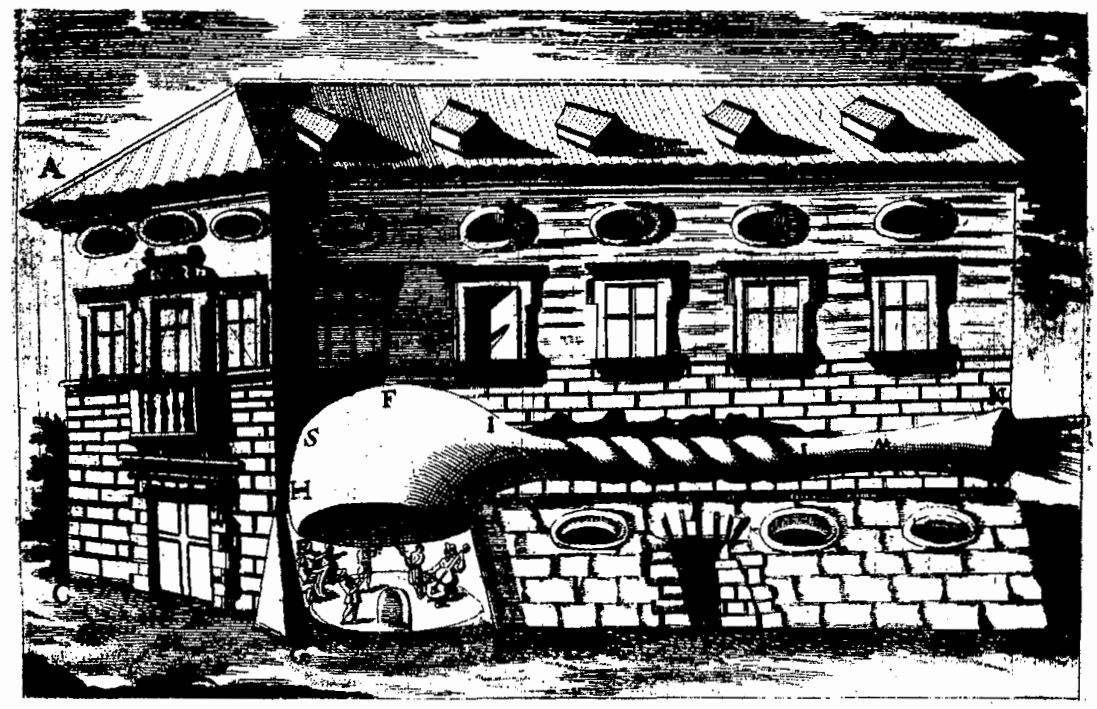

mejor conocido por su pseudónimo literario: Lenin.

Kerensky era un hombre instruido; asistió a la Universidad de San Petersburgo y se graduó en Leyes. Es probable que se haya "radicalizado" durante esa época por medio de sus contactos personales con estudiantes involucrados en protestas contra el régimen zarista. ${ }^{9}$ También aprovechó la oportunidad para leer una gran cantidad de libros que había prohibido el gobierno por su carácter subversivo. Al igual que Lenin, Kerensky estaba familiarizado con la obra de Karl Marx, pero decía que rechazaba la doctrina del materialismo histórico porque ne-

9 Para un análisis del proceso de "radicalización", véase el capítulo 9 de Rejai y Phillips, Leaders, 1979. gaba los "elementos eternos" de la naturaleza humana: "la bondad, la belleza, el amor y el odio". Para Kerensky, éstas eran las motivaciones más impor. tantes del comportamiento humano.

Madero era hijo de una acaudalada familia de hacendados del estado de Coahuila. Como tal, puede ser considerado miembro de la clase alta rural. También recibió una buena educación, en escuelas de México y del extranjero. Es difícil señalar los orígenes de la radicalización de Madero, pues no parece haber estado expuesto a ninguna influencia "subversiva" como las que afectaron a Kerensky. No obstante, durante sus viajes a Francia y Estados Unidos, las instituciones democráticas de estos países lo impresionaron en gran medida y esto pudo haber sido la fuente de su inspiración. 
Desde luego, ambos habían experimentado directamente los abusos de sus respectivos regímenes antiguos. De acuerdo con Rejai y Phillips, esto es una importante fuente de motivación para cualquier líder revolucionario. Los dirigentes revolucionarios suelen verse impulsados $\hat{p}$ or un sentido de injusticia y por la correspondiente misión de "arreglar las cosas". Este sentido de injusticia puede proceder de experiencias personales de humillación o brutalidad por parte del régimen vigente $o$ de haber presenciado actos de humillación o brutalidad cometidos contra otros. ${ }^{10}$

Este "sentido de la justicia" alentó a los dos hombres a reflexionar sobre las fallas de sus respectivos países; cada uno llegó finalmente a la conclusión de que en el meollo mismo del problema estaba el concepto del poder absoluto. Madero vio en la prolongada dictadura antidemocrática de Porfirio Díaz el origen de todos los infortunios de México."11 Para Kerensky, el "poder supremo" de la autocracia zarista era el culpable del "mal" que afligía a Rusia. ${ }^{12}$

Ambos, sin duda, estarían de acuerdo con el viejo lema "el poder absoluto lleva a la corrupción absoluta". Para los dos, el hombre que detentaba el poder era el verdadero enemigo del pueblo y constituía un obstáculo para el progreso significativo. La única solución, a su manera de ver, era arrebatar el poder de manos del individuo y ponerlo en manos de la mayoría, con

10 Ibid., p. 57.

11 Vease Ross, Francisco, 1955, p. 33.

12 Véase Kerensky, Russia, 1965, pp. 27-28. el apoyo de garantías contitucionales del derecho a ejercer dicho poder libremente. De acuerdo con Kerensky, el absolutismo debía ser reemplazado por un "gobierno democrático basado en el predominio de la ley y la justicia social". ${ }^{13}$ No cabe duda de que en este punto, Madero concordaría con él de todo corazón.

Motivados de esta manera para cambiar el sistema, Kerensky y Madero se aventuraron en carreras políticas como reformadores, jugando con las propias reglas del sistema, a fin de cambiarlo desde el interior. Kerensky adquirió renombre como abogado, defendiendo a los rusos y a las minorías étnicas acusados de crímenes contra el Estado. Irrumpió en escena en 1912, cuando defendió junto con otros abogados a un grupo de nacionalistas armenios enjuiciados por pertenecer a una organización revolucionaria. Después, en ese mismo año fue miembro de una comisión no oficial enviada a investigar la masacre de cerca de 170 mineros huelguistas en Lena, Siberia. Actividades como éstas le merecieron fama de "revolucionario" y le valieron un asiento en el Duma, en Petrogrado.

El Duma era un cuerpo representativo casi impotente, una de las concesiones sin sentido que Nicolás II hizo a la reforma en Rusia. Era un sitio donde los intelectuales y reformistas en representación de la mayor parte del espectro político, de la derecha a la izquierda, podían ventilar su furia contra el sistema y agitar para el cambio, siempre y cuando no perdieran la

13 Ibid., p. 219. 
calma (la policía zarista vigilaba a cada miembro y éstos no estaban dispuestos a tolerar más). Sin embargo, para una revolución prometedora éste era el sitio donde había que estar y Kerensky de inmediato se sintió como en casa. Miembro en secreto del Partido Socialista-Revolucionario aumentó su fama y popularidad con su crítica abierta al régimen y su disposición a arriesgarse a ser arrestado y encarcelado. De hecho en una ocasión lo arrestaron $y$, aunque al final fue puesto en libertad, este breve encarcelamiento fue su graduación en las filas de los verdaderos revolucionarios. ${ }^{14}$ Kerensky aún era miembro del Duma al inicio de 1917, cuando los esfuerzos que implicó la primera guerra mundial finalmente acabaron con el régimen zarista. Al igual que todos, fue tomado por sorpresa cuando el gobierno, de manera repentina, cayó sin luchar.

Madero hizo su parte por la democracia mexicana al tratar de establecer un partido de oposición viable para desafiar la hegemonía porfiriana en las urnas. Con varios de sus amigos organizó un club político que empezó a postular candidatos en las elecciones municipales y provinciales de su estado natal de Coahuila. Desde luego, ninguno de estos candidatos ganó; a los porfiristas no les divertía el movimiento e intentaron reprimirlo mediante la intimidación y el arresto inmediato de algunos de los miembros. El propio Madero pudo escapar de ser detenido (por lo menos en ese momento) y continuó con la lucha. Llegó a darse cuenta de que tendría

\footnotetext{
14 Abraham, Alexander, 1987 , pp. 33-35.
}

su mejor oportunidad para desafiar a Díaz y restaurar la democracia en México, durante las elecciones presidenciales de 1910. Incluso escribió un libro sobre el tema. ${ }^{15}$ Con este fin, Madero formó el partido antirreleccionista y se postuló para presidente con el popular lemáa "Sufragio efectivo. No reelección". Desafortunadamente, Díaz no era lo bastante justo para dejar que Madero ganara; de hecho, dispuso que el político coahuilense fuera encarcelado poco antes de las elecciones. Madero escapó y logró llegar a Texas, donde empezó a formular sus planes de una insurrección armada para derrocar a Porfirio Díaz.

Para Madero y Kerensky, estos esfuerzos por cambiar el sistema desde el interior resultaron infructuosos. No eran ni ingenuos ni estúpidos (por lo menos en este caso en particular). Al final, reconocieron que el verdadero cambio nunca podría ocurrir en sus respectivos países hasta que no se eliminaran estos grandes obstáculos, a saber: Porfirio Díaz y el zar Nicolás II. Por desgracia, si bien estos obstinados autócratas realmente representaban un serio impedimento para el cambio, sería peligroso suponer que una vez eliminado el obstáculo, todos vivirían felices para siempre. En el mundo real, a diferencia de los cuentos de hadas, al parecer siempre hay estorbos en el camino.

Hay una complicación adicional: al trabajar dentro del sistema imperante, uno empieza a considerar el aparato estatal como un campo de batalla del cambio político y no como

15 Véase Madero, Sucesión, 1911. 
una entidad política autónoma, que en sí misma necesita ser cambiada. Theda Skocpol señala la inquietante tendencia de los teóricos de la revolución a ver al Estado de esta manera. Tal vez este razonamiento debería extenderse incluso a los revolucionarios mismos. ${ }^{16} \mathrm{Si}$ un líder revolucionario considera el Estado como un campo de batalla para el cambio, icómo podría tener esperanzas de iniciar el proceso de construir un nuevo Estado? Tal hecho es en realidad el primer paso para originar cambios sustanciales.

Madero y Kerensky también parecen haber compartido posiciones similares con respecto al uso de la represión y de la violencia política (aunque al parecer, Kerensky no era tan escrupuloso como su contraparte). En México, podría decirse que el uso de la fuerza era el medio tradicional para conseguir y mantener el poder político, como lo demostró el propio Porfirio Díaz. No obstante, Madero rechazó este medio en forma continua y consistente. ${ }^{17}$

Madero fue el instigador de la revolución mexicana y parecía aceptar que la insurrección armada era la única forma de derrocar a Díaz, pero en el campo de batalla resultó ser un revolucionario bastante reacio. En varias ocasiones, Madero se detuvo cuando sus fuerzas estaban en posición de atacar ciudades tomadas por el ejército federal; además se mostró renuente a ordenar la ejecución de un comandante federal responsable de la masacre de va-

16 Skocpol, States, 1979, p. 25.

17 Ross, Francisco, 1955, p 39. rios revolucionarios apresados. ${ }^{18}$ Esta tendencia le provocó conflictos con sus generales Pascual Orozco y Pancho Villa, quienes empezaron a sospechar que actuaba con cobardía.

Pese a la renuencia de Madero para intensificar la lucha contra el ejército federal, Díaz finalmente fue obligado a renunciar y a abandonar el país. Madero tomó entonces medidas inmediatas para poner fin a las hostilidades y restaurar la paz y el orden en el país. ${ }^{19}$ En lo sucesivo no toleró la coerción ni la represión en su propio gobierno. Cuando su hermano Gustavo trató de organizar un grupo de matones para intimidar a sus oponentes políticos en la ciudad de México, Madero lo envió en misión diplomática a Japón para evitar cualquier confusión ulterior. ${ }^{20}$

Al principio, Kerensky tenía una posición más práctica en cuanto al uso de la violencia política; de hecho, antes de la caída del gobierno zarista, defendió el empleo que ciertos grupos de oposición hicieron del terrorismo. ${ }^{21}$. Sin embargo, después de que los moderados tomaron el poder, también él repudió el uso de la fuerza y llamó a la restauración de la paz y el orden (quizás por temor a que el terrorismo se dirigiera ahora contra el gobierno provisional). También estaba muy orgulloso del hecho de que su gobierno no hubiera cedido a la tentación de utilizar la coerción y la re. presión, evitando así la instauración de un terror "jacobino" en Rusia. La

\footnotetext{
18 Ibid.; p. 167.

19 Ibid., pp. $182-183$.

20 lbid., pp. 223-224.

21 Abraham, Alexander, 1987, p. 121.
} 


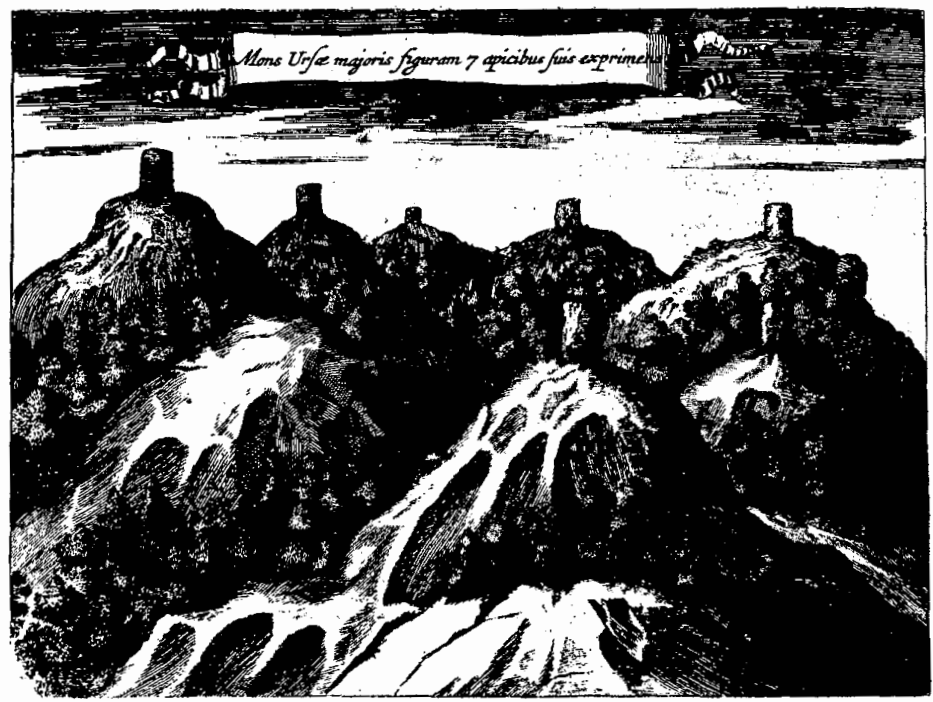

esencia de esta política fue captada en el "testamento político" publicado por el primer gobierno provisional:

El gobierno provisional [...] considera que el poder del Estado no deberia basarse en la violencia ni en la coerción, sino en el consentimiento de los ciudadanos libres a someterse al poder que etfos mismos han creado. ${ }^{22}$

Esta aversión a emplear la fuerza para suprimir a los oponentes políticos puede considerarse una seria debilidad, si se acepta el razonamiento de Crane Brinton de que los moderados fracasaron, por lo menos en parte, porque no eran tan "despiada-

2 Ibid., p. 185. dos" como los enemigos a quienes se enfrentaron, tanto de la derecha como de la izquierda. Por otra parte, Brinton también da a entender que de cualquier forma los moderados no estaban en muy buena posición para reprimir. Sostiene que, en el caso de Kerensky, cualquier uso de la fuerza hubiera provocado la protesta inmediata de sus oponentes y hábilmente habría hecho el juego a los propagandistas bolcheviques. ${ }^{23}$ Como ejemplo, cita el intento de suprimir a los bolcheviques después de los "disturbios de julio" que instigaron en Petrogrado. Los bolcheviques provocaron una tormenta de protestas públicas que acusaban al gobierno provisional de "despotismo y zarismo del peor género". El gobierno

23 Brinton, Anatomy, 1965, p. 138. 
cedió dócilmente. Esto parecería indicar que Kerensky estaba atado de manos con respecto al uso de la represión.

No obstante, el hecho de que los bolcheviques una vez en el poder no hayan dudado en emplear la represión contra sus oponentes políticos $-\mathrm{y}$ con bastante éxito- demuestra algo diferente. El asunto no era quién usaba la represión, sino con cuánta eficacia la empleaba. Tal vez si Kerensky hubiera sido un poco más autoritario con la oposición -en especial con los bolcheviques-Lenin habría sido quien pasara el resto de su vida como exiliado político en el extranjero.

Un último factor ideológico común a Madero y Kerensky se refiere a lo que podría llamarse su "fe" en la naturaleza humana. Madero había iniciado su movimiento político creyendo que el pueblo mexicano en verdad estaba listo para la democracia. ${ }^{24}$ Aunque quizá se volviera algo cínico durante los últimos días de su mandato, Madero nunca dejó de creer que esta apreciación era justa. ${ }^{25}$ Tal vez, con un pequeño "empujón" en la dirección adecuada, podría crear un nuevo México donde todas las facciones y todos los intereses cooperarian en beneficio de todos los mexicanos. Por lo menos Madero esperaba fervientemente que éste fuera el caso; al final arriesgó su vida misma por ello.

Es evidente que, aunque no era tan optimista, Kerensky creía que los seres humanos, en ocasiones, toman el

24 Véase Madero, Sucestón, 1911, pp. 303311, "El pueblo mexicano está apto para la democracia..."

25 Ross, Francisco, 1955, pp. 276 y 339. camino equivocado, pero que en el fondo tienen buen corazón; algunas palabras sabias a tiempo serían suficientes para hacerlos reconocer su insensatez y regresarlos al buen camino. Pueden encontrarse amplias pruebas de este convencimiento en su propia habilidad para restaurar la moral en el ejército ruso durante sus visitas al frente. ${ }^{26}$ Es interesante comparar el mensaje de Kerensky a los soldados ru. sos con lo que Lenin les decía casi al mismo tiempo. Este último decía:

Los convocamos a una revolución social. ilos llamamos no a morir por otros, sino a destruir a otros, a destruir a sus enemigos de clase en el frente interno!

Kerensky, por otra parte, decía lo siguiente:

Es fácil llamar a hombres exhaustos a dejar sus armas $e$ irse a casa, donde se ha iniciado una nueva vida. Pero yo los convoco a la batalla, a hazañas de heroísmo; no los convoco a la festividad, sino a la muerte; ia sacrificarse para salvar a su país! $!^{27}$

Cualquiera que pudiera creer que el

26 Kerensky, Russia, 1965, pp. 268-288, dedica todo un capítulo a sus esfuerzos por restaurar la moral en el frente como preparación para la gran ofensiva de julio de 1917. Menciona con frecuencia la "fe renovada" y el "espíritu de lucha" que encendían entre las tropas sus discursos patrióticos. Uno se pregunta cuánto durarían estos sentimientos después de que Kerensky se alejaba para dirigirse hacia el siguiente grupo de soldados.

27 Ibid., p. 277. Kerensky no proporciona la fuente de la cita de Lenin. 
soldado ruso común preferiría el segundo mensaje al primero -después de cuatro años de muerte $y$ destrucción infinitas, por diversos medios desagradables- seguramente debió tener una gran fe en la naturaleza humana.

El peligro inherente a esta "fe" no era tanto que Madero y Kerensky pretendieran ampliar los motivos humanitarios y las intenciones benévolas a sus enemigos, sino que se inclinaban a creer que el "pueblo" lograría ver más allá de las mentiras de la oposición y se uniría a la causa que en última instancia serviría a sus mejores intereses; en otras palabras, la causa de los moderados. Por desgracia, no siempre se puede confiar en que el pueblo reconocerá sus intereses, $y$ mucho menos que actuará conforme a ellos de manera racional, sobre todo cuando es confrontado con dos o más interpretaciones contradictorias sobre cuáles deberían ser esos intereses.

\section{GOBIERNO PROVISIONAL}

Tanto en Rusia como en México, el régimen de los moderados empezó con un gobierno provisional, una fase intermedia entre el antiguo gobierno "malo" y el nuevo gobierno "bueno" que vendría. El gobierno de Madero lograría sobrevivir a esta etapa, no así el de Kerensky. Sin embargo, puede argüirse que en ambos casos la fase provisional finalmente dio origen a las fuerzas que derrocarían a los moderados y alimentó su crecimiento.

Claro que si para el éxito de la revolución se requiere la construcción de un Estado, entonces es obvio que no resulta muy buena la idea de aplazar el proceso hasta una imprecisa fecha futura. En lugar de asumir el poder durante el júbilo y el apoyo popular que sucedieron a la caída de los tiranos, los moderados eligieron esperar y asumir el poder mediante el camino legal de las elecciones democráticas. Esta expresión de la voluntad popular -en México por medio de las elecciones presidenciales fijadas para 1911 y en Rusia mediante la asamblea constituyente que se convocaría en 1918se planeó de manera conveniente (y fatídica) para varios meses después.

El hecho de que las fuerzas de los antiguos regímenes nunca hubieran sido derrotadas de un modo decisivo, planteó desde un principio serias complicaciones a ambos gobiernos provisionales. Los tiranos habían capitulado frente a to que parecía ser una oposición popular abrumadora, pero las elites burocráticas y militares de sus regímenes no se habían rendido con ellos.

Cuando cayó la monarquía rusa en febrero de 1917, el gobierno provisional heredó todos los miembros del antiguo Duma -radicales y conservadores por igual- junto con el ejército en su conjunto y la burocracia zarista. (Los problemas con el ejército se examinarán con mayor detalle más adelante.) Los conservadores dentro del propio gobierno provisional habrían de ocasionar interminables problemas al pobre Kerensky. Por ejemplo, cuando varios miembros del gabinete parecían estar a favor de preservar la monarquía bajo el gran duque Michael, el hermano del zar, se oca- 
sionó una violenta protesta pública. ${ }^{28}$ Asimismo, el ministro de Relaciones Exteriores, el conservador P. N. Miliukov, provocó la primera crisis ministerial del gobierno, al abogar obstinadamente por la continuación de los objetivos de guerra imperialistas del régimen zarista. Esto no era recibido con gusto por las masas, cansadas de guerra. ${ }^{29}$ Muchos de los miembros fueron objeto de purgas paulatinas, pero no antes de haber provocado un daño irreparable a la imagen pública del gobierno.

A esto se sumaban mayores complicaciones, pues los conservadores, intransigentes con frecuencia, obstruían la aprobación de las controvertidas reformas sociales. El gobierno provisional encontró una brillante solución para este problema: posponer dichas reformas indefinidamente. Como señala Richard Abraham: "Siempre que los Cadetes [la fracción conservadora] consideraban que la legislación era demasiado radical, invocaban la competencia omnipresente de la asamblea constituyente". ${ }^{30}$

La consecuencia fue que el gobierno provisional nunca llegó a tratar los asuntos que preocupaban a la mayoría de los rusos. Las reformas importantes tendrían que esperar hasta que la asamblea constituyente se reuniera. La pregunta era si el pueblo ruso estaba dispuesto a esperar tanto. En retrospectiva, es evidente que no lo estaba.

28 Ibid., pp. 211-216; Abraham, Alexander, 1987 , pp. 143-145.

29 Véase Kerensky, Russia, 1965, pp. 242 249.

${ }^{30}$ Abraham, Alexander, 1987, pp. 220.
En el caso de Madero, la situación dentro del gobierno interino era especialmente destructiva. El arreglo que había convenido en Ciudad Juárez dio cuenta de Porfirio Díaz, pero dejó un gabinete interino repleto de porfiristas $y$ un presidente interino predispuesto en definitiva a favor de los grupos de interés del antiguo régimen. ${ }^{31}$ Los conservadores de este gabinete de coalición, al igual que los pertenecientes al gobierno provisional de Kerensky, bloquearon las iniciativas de reforma de los revolucionarios. El conflicto entre las dos facciones opositoras paralizó el resto de la burocracia y debilitó la confianza pública. Peor aún, los líderes de la revolución empezaron a perder la fe en el propio Madero, quien parecía complacer a los reaccionarios. Hubo algunas renuncias en el gabinete, así como también las habría en el gobierno de Kerensky. Para gran infortunio de Madero las purgas en $s u$ gobierno siguieron la dirección contraria: a la larga los revolucionarios fueron reemplazados por antiguos porfiristas, con lo cual el equilibrio se inclinó aún más a favor de las viejas elites. ${ }^{32}$

Madero estaba consciente de esos problemas, pero no le preocupaban demasiado. En su optimismo estaba seguro de que las próximas elecciones presidenciales lo resolverían todo (es evidente que no había dudas sobre su triunfo). Esperaba con ansia la reivindicación el día en que se emitieran los votos y anticipaba la fecha, com-

31 Ross, Francisco, 1955, pp. 177-1:'8; Aguirre Benavides, Errores, 1980, pp. 41-44

32 Ross, Francisco, pp. 203-205. 
parándola con el día del juicio final y el segundo advenimiento, con la esperanza de que su confirmación mediante las elecciones, provocaría una redención equivalente de sus pecados políticos.

Esta fe se ejemplifica con la relación entre Madero y Emiliano Zapata, el líder revolucionario de Morelos. Aunque ambos dirigentes habían sufrido un grave distanciamiento durante la presidencia interina de Francisco León de la Barra -causada tanto por la ineptitud de Madero, como por las intrigas de los reaccionarios- Madero estaba convencido de que una vez que asumiera la presidencia, el rebelde de Morelos simplemente "depondría sus armas" sabiendo que él (Madero) permanecería leal a sus "primeras propuestas" sin importar lo que hiciera mientras tanto De la Barra. 33 Entonces, su. puestamente los dos se saludarían con un abrazo y un amistoso golpe en la espalda. De hecho se cree que, no mu. cho después de iniciado el mandato de Madero, Zapata se ofreció a ir a la ciudad de México y colgar en persona al nuevo presidente del árbol más alto de Chapultepec. ${ }^{34}$

\section{EL EJÉRCITO}

Las intrigas de los burócratas reaccionarios representaban un peligro menor si se comparaban con el hecho de que el alto mando de ambos ejércitos, la elite misma de los cuerpos oficiales del antiguo régimen, seguía siendo

33 Ibid., pp. 201.

34 Véase Womack, Zapata, 1968, p. 127. casi el mismo. Aunque quizá en ambos casos los funcionarios de alto rango reconocieran que el antiguo régimen estaba muerto, llegaron a despreciar a los "apocados" de los gobiernos provisionales por sus débiles políticas hacia los revolucionarios radicales, simpatizando con las preocupaciones de las antiguas elites.

Al parecer, Madero temía a los militares, y con razón. Adoptó una política en extremo conservadora con respecto al ejército federal ${ }^{35} \mathrm{Al}$ mismo tiempo, sugirió que el presidente De la Barra realizara algunos cambios en el mando del ejército, con el fin de eliminar a algunos de los jefes que pudieran darle la espalda. Nunca in. sistió en que se llevaran a cabo dichos cambios. ${ }^{36}$ Como resultado, el ejército federal nunca estuvo bajo su control de manera efectiva, $y$ de hecho actuó contra sus designios. Al final, un oficial que el propio Madero había colocado al mando de las tropas federales en la capital -Victoriano Huertapuso fin a su breve carrera revolucionaria, por medio de un golpe de Estado.

Asimismo, Madero había tomado una decisión fatal que a final de cuentas lo hizo vulnerable al golpe de Estado de Huerta. Como gesto conciliador hacia el ejército federal y los conservadores, Madero llamó al licenciamiento de los ejércitos revolucionarios que lo habían puesto en el poder. Esta medida, en efecto, privó al gobierno de Madero de un apoyo militar independiente y dejó su destino

35 Ross, Francisco, 1955, p. 180.

36 Ibid., p. 199. 
en manos del ejército federal. ${ }^{37}$ Todavía peor, parecia que Madero daba la espalda a sus aliados revolucionarios y a su causa, lo que prácticamente representaba una traición con la que los libraba a las fuerzas reaccionarias. ${ }^{38}$ Como ejemplo, los torpes esfuerzos de Madero para negociar la disolución de las tropas revolucionarias de Zapata en Morelos -a pesar de que el general Huerta desplegaba en este estado una columna de tropas federales para arremeter contra los rebeldes- convencieron a Zapata de que no podía confiarse en Madero. 39

La situación de Kerensky era igualmente precaria y no se dio cuenta de ella hasta que fue demasiado tarde. Kerensky hizo concesiones al alto mando ruso no por miedo, sino porque $\mathrm{Ru}$ sia estaba atorada en una guerra con Alemania y el gobierno provisional es peraba lograr una victoria rápida. Sin embargo, a diferencia de Madero, Kerensky tuvo que enfrentarse con tropas rebeldes y generales reaccionarios. Al principio de la revolución, muchos soldados y marinos se habían amotinado y recurrido a los soviets de los trabajadores en busca de dirección; los sovtets, a su vez, procuraron su apoyo activamente formando "secciones militares" y emitiendo una "Decla. ración de los derechos de los soldados". Ia sección militar en Petrogrado tenía tanta autoridad entre las tropas como la cadena de mando del ejército oficial, o quizá más. ${ }^{40}$

37 Ibid., pp. 185. 58-59.

38 Aguirre Benavides, Errores, 1980, pp.

39 Vease Womack, Zapata, 1968, pp. 97-128.

to Kerensky, Russia, 1965, p. 203.
Kerensky estaba obligado a mantener un equilibrio entre los intereses de los dos grupos (soldados y oficiales) para conservar el control del ejército, pero al final este control sería quebrantado por un intento de golpe de Estado del alto mando. El general Lavr Kornilov, a quien Kerensky nombró jefe supremo, había planeado marchar sobre Petrogrado y derrocar al gobierno provisional. Sólo la torpeza de último momento de los conspiradores puso a Kerensky sobre aviso de la conspiración. Por su parte, hizo público el complot y soldados leales al soviet de Petrogrado se unieron para frustrar los planes de Kornilov en el momento en que sus tropas se acercaban a la ciudad. En adelante ya no se podia confiar en el alto mando como medio para controlar el ejército desde ariba y el incidente habría de tener serias repercusiones a lo largo del gobierno provisional. Como señala George Katkov, el asunto Kornilov

contribuy 6 en gran medida a la desorganización del ejército y a la pérdida de autoridad de sus jefes. También condujo a una completa desorientación de los líderes políticos del ala derechista, tanto los socialistas, como los liberales, que apoyaban al gobierno provisional. ${ }^{41}$

El mismo Kerensky había sido acusado de complicidad en la conspiración de Kornilov; de hecho, se sugería que deliberadamente había postergado la denuncia del complot con

11 Katkov, Kornilou, 1980, p. 161. 
la esperanza de que Kornilov acabara con los bolcheviques de una vez y para siempre. ${ }^{42}$ Ya sea que esto fuera cierto o no, en adelante se sospechó de Kerensky y la escasa influencia que tenía sobre las tropas empezó a disminuir.

Desde luego que los soldados comunes habían sospechado siempre de los motivos de Kerensky, quien cometió el error fatal de ponerse de parte de los miembros del gobierno provisional, quienes estaban a favor de continuar la guerra con Alemania, la misma guerra que había incitado a las tropas de Petrogrado a sublevarse en lugar de marchar hacia el frente y que, de esta manera, había ocasionado ya el derrumbe del gobierno zarista. Su intención de luchar hasta alcanzar la victoria final sólo sirvió para enemistarlo con los soldados cansados de la guerra y para crear otra vía de ataque para la propaganda bolchevique. ${ }^{43}$ Aunque es cierto que los aliados lo presionaban para que prolongara la guerra, también creía firmemente que una derrota de éstos sólo podía acabar conduciendo al fracaso de la revolución. Así, para salvar a "su" Rusia -la nueva Rusia libre-, Alemania tenía que ser derrotada a como diera lugar. ${ }^{44}$

Resulta paradójico que Kerensky haya tomado una posición tan firme en este asunto, pues antes de la revolución había vacilado entre un apoyo tibio y una oposición vehemente al esfuerzo bélico, adaptando su propia opinión a los cambios del clima

42 Ibid., p. 353; véase también Mackenzie y Curran, History, 1987, pp. 593-595. 590.

23 MacKenzie y Curran, History, 1987, p.

Kerensky, Russia, 1965, pp. 267. político ${ }^{45}$ Continúa poco claro el razonamiento que sustentó su decisión posterior de apoyar la guerra, sobre todo en un momento en que la opinión pública, influida por la propaganda antibélica bolchevique, se oponía a ella por mayoría casi abrumadora. Más paradójico aún resulta el hecho de que al principio los bolcheviques habían mostrado su apoyo al esfuerzo bélico, como lo revela el estilo inspirado de un artículo de Pravda escrito por un joven patriota bolchevique que se hacía llamar José Stalin. El argumento principal del artículo era el siguiente:

Cuando un ejército se enfrenta a otro, la política más absurda sería proponer que alguno de los dos depusiera las armas y regresara a su casa. Esta política no sería una política de paz, sino de esclavitud, una política que el pueblo libre rechazaría indignado. No, el pueblo libre se mantendrá firme en sus puestos, responderá bala por bala y granada por granada. Esto es lo inevitable. ${ }^{46}$

Tan pronto como Lenin regres $\delta$ del exilio puso un alto inmediato a esta insensatez. Podía ver en qué dirección soplaban los vientos del sentimiento

45 Abraham, Alexander, 1987, pp. 79, 89-99, 111. Al principio, Kerensky alentó a los rusos a que defendieran su territorio para que pudieran liberarlo. De esta postura paśo a una oposición abierta, sólo para volver después a apoyar una guerra puramente defensiva. Poco antes de la revolución, Kerensky demandaba una paz con Alemania independiente de los aliados, para evitar que se siguieran dilapidando los recursos de Rusia en una guerra que "el pueblo no apoyaba".

${ }^{46}$ Kerensky, Russia, 1965, pp. 261-262. 
público. A partir de ese momento la campaña antibélica bolchevique em. pezó en serio, con gran perjuicio de Kerensky.

La fuerza militar es uno de los pilares de todo gobierno revolucionario, sobre todo al enfrentarse con una oposición armada (de la derecha o de la izquierda). Cuando los moderados destruyeron su apoyo militar, lógicamente se volvieron vulnerables al ataque. Si Kerensky y Madero hubieran sido capaces de prever las consecuencias de sus decisiones respecto a la situación militar, de seguro habrían tomado cursos de acción diferentes. Desafortunadamente carecían, tanto de la visión retrospectiva con que contamos nosotros, como de la astucia política de sus sucesores.

\section{RELACIONES INTERNACIONALES}

Otro factor que se relaciona en forma directa con la cuestión militar se refiere al papel de las influencias internacionales externas. Tanto en México como en Rusia los moderados estaban presionados por gobiernos extranjeros; gobiernos conocidos por sus in. clinaciones imperialistas, podría agregarse. Para México, era el coloso del norte, Estados Unidos. El gobierno estadunidense estaba sumamente preocupado por el destino de sus ciudadanos y de sus propiedades en México e incluso amenazó con la intervención si el gobierno de Madero no tomaba medidas para garantizar la seguridad de éstos.

Por su parte, Rusia estaba presionada por los gobiernos aliados, sobre todo por Gran Bretaña, que temían que el frente oriental cayera, pues entonces Alemania quedaría libre para dirigir su atención a occidente. Kerensky trató de satisfacer sus demandas, pero la situación militar de Rusia era caótica y Alemania parecía llevar la voz cantante. Los aliados no estaban satisfechos con los esfuerzos que los moderados desempeñaban en Rusia; lo mismo puede decirse respecto a Estados Unidos y Madero. Los representantes acreditados expresaban su descontento ante los gobiernos revolucionarios.

Hay en México un punto que obviamente debe quedar establecido: Henry Lane Wilson, embajador estadu. nidense en México, se mostraba abiertamente hostil hacia el gobierno de Madero y pronto se convirtió en el más severo crítico del régimen ${ }^{47}$ Cuando empezó a planear su golpe de Estado, el general Huerta se dio cuenta de que, si quería tener éxito, el reconocimiento de Estados Unidos era esencial. Con esta idea en mente, entabló relación con el embajador Wilson y lo hizo partícipe de la conspiración. No se sabe hasta qué punto Wilson fué cómplice y tal vez nunca se sepa; sin embargo, tan sólo por alentar de manera tácita a Huerta debe atribuírsele parte de la culpa por lo que ocurrió.

En Rusia hubo circunstancias notablemente similares. Los gobiernos aliados presionaban al gobierno provisional para que siguiera en pie de guerra y se mostraban preocupados ante las intenciones de los revolucio-

17 Ross, Francisco, 1955, p. 237. 
narios radicales (en especial de los bolcheviques, pues se sabía que estaban negociando con los alemanes). Cuando el general Kornilov planeaba la conspiración, recurrió al embajador británico en busca de apoyo -incluyendo vehículos blindados- igual que Huerta había recurrido a Wilson. ${ }^{48}$ El embajador británico, cuyas normas éticas eran, al parecer, más elevadas que las de su contraparte de Estados Unidos, se negó a participar en la conspiración; pero tampoco se tomó la molestia de advertir a Kerensky sobre el complot y, lo que es bastante extraño, durante la marcha sobre Petrogrado efectivamente había en la columna de Kornilov vehículos blindados británicos.

48 Kerensky, Russia, 1965, pp. 343-344.
Es dificil determinar en forma exacta qué tanta influencia ejercieron estas fuerzas exteriores en los acontecimientos internos. Sin embargo, es claro que los moderados sentían cierta dependencia de la buena voluntad de los países que los presionaban, y tanto Madero como Kerensky hicieron esfuerzos especiales para apaciguarlos. También debe recordarse que antes de las dos revoluciones, las relaciones de México y Rusia con las potencias imperialistas eran desiguales, tal vez incluso de dependencia; hecho significativo, sobre todo a la luz del análisis de Theda Skocpol, que aborda las relaciones transnacionales y la competencia entre Estados.

¿En qué se equivocaron Madero y Kerensky? Quizás puede encontrarse una respuesta a esta pregunta en las

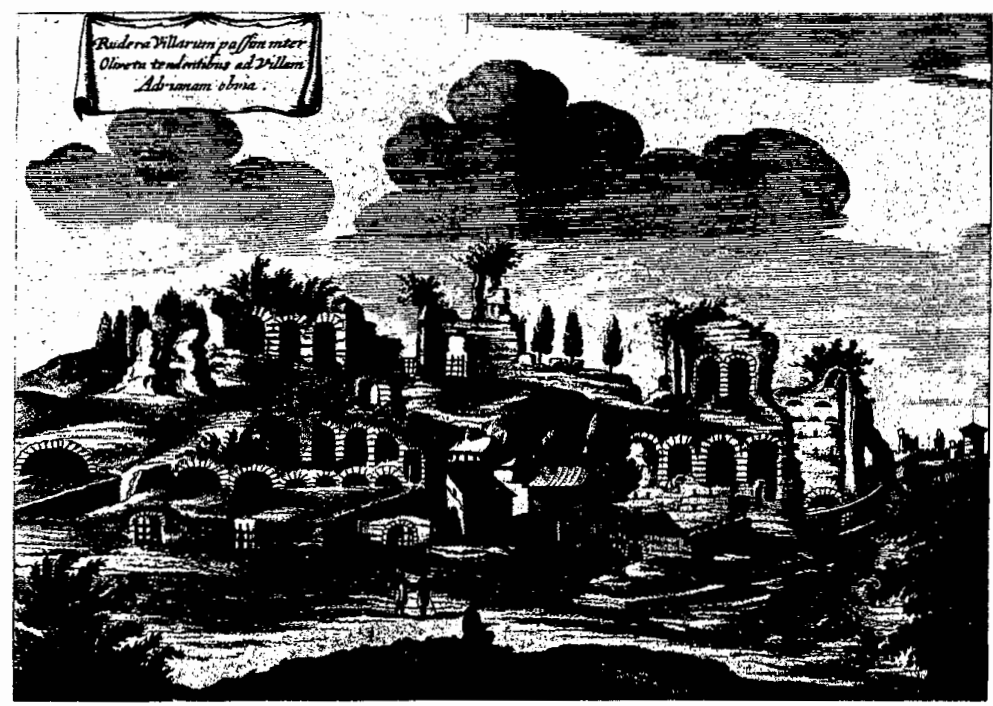


acciones de sus sucesores. En ambos países los revolucionarios, que al final llegaron al poder, adoptaron una posición muy desafiante hacia los imperialistas y resistieron la presión de éstos, incluso frente a la intervención.

\section{¿REFORMA AGRARIA O LIBERTADES CIVILES?}

Recordemos que los moderados destruyeron en la práctica su base de apoyo militar independiente mediante una serie de imprudentes decisiones. Asimismo, en el campo de la reforma, una serie de opciones equivocadas habrían de negarles la oportunidad de crear bases de apoyo político popular. La reforma agraria era una preocupación preponderante para el proletariado rural, tanto en Rusia como en México. Desde el punto de vista de los campesinos, era la causa de haber luchado en la revolución. Sin embargo, en ninguno de los dos casos se apresuraron los moderados a actuar para satisfacer la demanda de reformas en la cuestión agraria, medida que con certeza hubiera contribuido a consolidar su base de poder.

Madero, obedeciendo a los dictados de su ideología personal -y tal vez influido por sus antecedentes como hacendado- insistía en que la reforma agraria en México no podía tener lugar sin antes realizar un "estudio cuidadoso y con perfecto arreglo a la ley". 49 Para los campesinos que ya habian empezado a reclamar sus tierras, ésta era una noticia muy inquietante. Madero debió haberse perca-

19 Ross, Francisco, 1955, p. 188. tado de ello; durante un encuentro especialmente dramático entre él y Zapata, el jefe rebelde estableció muy en claro-mediante un aire de grave violencia- que su pueblo ya había esperado lo suficiente para que le restituyeran sus tierras ancestrales. ${ }^{50}$

Cuando el gobierno provisional de Kerensky se mostró renuente a emprender reformas en la cuestion agraria, los campesinos rusos también tomaron el asunto en sus propias manos; expulsaron a los terratenientes, ocuparon las tierras y expropiaron (o en algunos casos destruyeron) las cosechas. Temiendo que estas expropiaciones pusieran en peligro su empresa bélica, el gobierno provisional respondió tratando de suprimir tales actos, recurriendo a veces a la fuerza armada. ${ }^{51}$ Esto no dio a Kerensky ninguna fama como héroe de la reforma agraria a los ojos del campesinado ruso.

De hecho, los miembros del gobierno provisional habían propuesto una gran cantidad de leyes respecto al problema de la tierra. Por desgracia, la reforma agraria era un tema delicado para los conservadores y se convirtió en otro más de los asuntos reservados para la asamblea constituyente, en donde habrían de discutirse con el mayor detalle las ramificaciones e implicaciones de la cuestión agraria. ${ }^{52}$

Por otra parte, ni Madero ni Kerensky se mostraron renuentes a otra de las áreas de reforma: las libertades civiles. Entre ellas ocupaba el pri-

\footnotetext{
30 Womack, Zapata, 1968, p. 96.

S1 Kerensky, Russia, 1965, pp. 224-225.

52 Abraham, Alexander, 1987, p. 161.
} 
mer lugar la libertad de expresión y de prensa, comunes en ambos gobiernos provisionales. En México, la libertad de prensa proporcionó a los reaccionarios un arma fácil para atacar a Madero y a la revolución. ${ }^{53}$ Además la prensa maderista estaba mal organizada y era ineficaz.

En Rusia la prensa libre dio a los bolcheviques y a los radicales un medio para difundir su propaganda con. tra el gobierno provisional, sin temor a represalias. Además, aunque era un brillante orador, el propio Kerensky no empleó la propaganda con eficacia. En cierto momento el gobierno provisional llegó a poseer pruebas de que Lenin había recibido fondos de Alemania y lo acusó de ser un agente alemán. Bien difundida, esta información podía haberse utilizado para desacreditar por completo a los bolcheviques $\rightarrow$ por lo menos a Leninpero sólo recibió una cobertura esporádica en la prensa; Lenin pudo así escapar del arresto y abandonó el país temporalmente, si bien desde el exilio siguió dirigiendo ataques contra el gobierno y regresó a Rusia en cuanto se olvidó el incidente. ${ }^{54}$

En general, aunque los derechos civiles y las libertades individuales constituyen la base misma de cualquier sociedad democrática estable, quizá no tengan lugar en una situación revolu. cionaria. Cuando Madero y Kerensky ampliaron esas libertades para los pueblos de sus países lo hicieron también para sus enemigos, quienes les dieron

53 Ross, Franctsco, 1955, pp. 179-180.

54 MacKenzie y Curran, History, 1987, p. 592.

buen uso atacando al nuevo gobierno sin temor al castigo. Para los moderados esto origino un serio dilema. A fin de poder responder a los ataques de sus enemigos, tendrian que haber estado preparados para arrestarlos y encarcelarlos, negarles sus derechos civiles $y$, de ser preciso, reprimirlos con la fuerza física. En efecto, habrían tenido que recurrir a los métodos de la odiada tiranía que acababan de derrocar y no estaban dispuestos a hacerlo.

Al rechazar el recurso de la fuerza coercitiva para suprimir a la oposición, los moderados prácticamente dejaron a sus enemigos las manos libres para que usaran cualquier medio para derrotarlos y, al negarse a violar los de. rechos de la minoría, tanto Kerensky como Madero sacrificaron en última instancia el poder de defender los derechos de la mayoría.

\section{RESUMEN}

Tanto en México como en Rusia, la fase del gobierno provisional estableció las bases para la caída de los moderados. En primer lugar, al crear un gobierno de coalición que incluía a los reaccionarios que después los traicionaron, debilitaron sus propias instituciones burocráticas y destruyeron toda posibilidad de lograr un consenso sobre decisiones políticas. Además, por dejar intacto el ejército del antiguo régimen, dejaron un arma peligrosa en manos de sus enemigos.

Por otra parte, debilitaron a sus gobiernos al no procurarse fuentes de apoyo popular o -como en el caso de Madero- al rechazarlas activamente. 
Un político astuto habría reconocido la importancia de la reforma agraria como medio para ganarse la lealtad de los campesinos y ningún revolucionario en su sano juicio habría dispersado a su propio ejército frente a una oposición armada y aún no derrotada.

Lo más importante es que ni Madero ni Kerensky iniciaron la tarea de construcción del Estado mientras su poder político y su apoyo popular estaban en su máximo nivel, simplemente el proceso entero se pospuso para una fecha futura. Esta decisión habría de tener graves consecuencias: en el momento preciso en que la gente requería un gobierno unificado y fuerte, que pudiera satisfacer las demandas de reformas materiales, se les proporcionó el espectáculo de facciones que disputaban entre sí y se les dijo que deberían esperar. Mientras tanto, los reaccionarios permanecían tranquilos, buscando la ocasión de explotar la debilidad de los gobiernos provisionales. Como señala Stanley Ross de manera sucinta, aunque Madero ganó la presidencia en las elecciones de 1911, fue una victoria vana:

En interés de la cooperación y la legalidad, Madero había cometido un gran error político. En lugar de asumir el poder como un líder revolucionario en su momento de triunfo, apoyado unánimemente por sus seguidores, Madero iniciaba su mandato con un prestigio $y$ una popularidad mermados, con sus partidarios divididos y con la continuación de disturbios en el país. 55

35 Ross, Francisco, 1955, p. 216.
En ese momento, abandonado por los revolucionarios y traicionado por los reaccionarios, Madero contaba, si acaso, con escasas posibilidades de éxito. A un año de su toma de posesión, fue víctima del golpe de Estado de Huerta y luego, al final, de las balas de los matones de éste. El gobierno de Kerensky ai siquiera duró tanto y nunca escapó a la fase provisional. Por lo menos él escapó de la muerte.

\section{CONCLUSIONES}

Las condiciones estructurales de la revolución crearon las opciones disponibles para los moderados; ni psicológica, ni ideológicamente Madero y Kerensky se hallaban en posición de reconocer y aprovechar dichas opciones. Como sin duda admitiría Skocpol, las revoluciones no pueden lograr que de repente todo se haga posible; siem. pre existen límites en cuanto a lo que puede y no puede hacerse, aun si los líderes son superhombres visionarios.

Podemos admitir que la consolidación del poder se encontraba dentro del ámbito de lo posible en Rusia y en México, ya que a la larga se logró en ambos casos. Tal vez pueda pensarse incluso que Madero y Kerensky la habrían alcanzado si hubieran tenido ya no visión, sino por lo me. nos una orientación ideológica ligeramente distinta.

Madero y Kerensky se guiaban por los dictados de sus propias personalidades e ideologías. Creían en lo que estaban haciendo y, a la inversa, sólo podían hacer aquello en lo que creían. Desafortunadamente, les fue imposi- 
ble alcanzar sus metas siguiendo el camino que habían elegido y sus filosofias no les permitieron buscar una vía alternativa que habría puesto en aprietos su fe en el predominio de la ley. Un revolucionario -revolucionario de éxito- supuestamente no se preocupa por tales sutilezas legalistas. Como lo indican Rejai y Phillips: "La ideología revolucionaria debe ser flexible y oportunista, y debe dejar un amplio margen para maniobras y concesiones." 56

A Madero y Kerensky no les preocupaba la construcción del Estado porque no se centraban en la consolidación del poder. Su objetivo era la $l i$ beralización y descentralización. Demasiado poder en un solo lugar era el mal que acababan de derrotar y luchaban por no caer en la misma trampa, mediante la promoción intencional de un gobierno central débil y el rechazo a la fuerza coercitiva del Estado. Para un revolucionario, ésta es una política de autodestrucción.

\$6 Rejai y Phillips, Leaders, 1979, p. 201.

\section{BIBLIOGRAFía}

-Abraham, Richard, Alexander Kerensky, the first love of the revolution, Columbia University Press, Nueva York, 1987.

-Aguirre Benavides, Adrián, Emores de Madero, Editorial Jus, México, 1980.

-Brinton, Crane, The anatomy of revo.

lution, Random House, Nueva York, 1965. -Katkov, George, The Kornilov affair: Kerensky and the break-up of the russian army, Longman Group, Londres, 1980.

-Kerensky, Alexander, Russia and bistory's turning point, Duell, Sloan and Pierce, Nueva York, 1965.

-Mackenzie, David y Michael Curran, A bistory of Russia and the Soviet Union, Dorsey Press, Chicago, 1987.

-Madero, Francisco I., La sucesión presidencial en 1910, $2^{\mathrm{a}}$ ed., Librería de la viuda de Ch. Bouret, México, 1911.

-Rejai, Mostafá y Kay Phillips, Leaders of revolution, Sage Publications, Beverly Hills-Londres, 1979.

-Ross, Stanley, Francisco I. Madero, apostle of mexican democracy, Columbia University Press, Nueva York, 1955.

-Skocpol, Theda, States and social revolution, Cambridge University Press, Cambridge, 1979.

-Womack, John, Zapata and the mexican revolution, Vintage Books-Random House, Nueva York, 1968. 